\title{
Caracterização de fatores relacionados com a decisão de compra, hábitos e preferências para o consumo de pescado entre frequentadores do Mercado Municipal de São Paulo
}

\section{Characterization of factors related to buying decisions and preferences for fish consumption in São Paulo, Municipal Market}

\section{Resumo}

Este estudo foi realizado para identificar os fatores relacionados com o consumo de pescado no Mercado Municipal Paulistano (MMP). Para esse fim, foram entrevistadas 100 pessoas: $65 \mathrm{mu}$ Iheres e 35 homens. Os entrevistados responderam a um questionário, preparado com perguntas abertas e fechadas sobre as características gerais do consumidor e o hábito de consumo de pescado. Os dados resultantes da pesquisa foram tabulados em um software de edição de planilhas a partir das quais foram construídos gráficos e tabelas. A maioria dos entrevistados era mulher e possuía residência e origem no município de São Paulo. Metade dos entrevistados relatou ir raramente ao mercado e os que iam com frequência indicaram que a variedade e a qualidade do produto são fatores importantes no MMP. Observa-se que os fatores que mais dificultam o consumo de pescado são o preço e a falta de hábito de consumo do produto pelos entrevistados. Conclui-se que o Mercado Municipal é uma local com muitas opções e com produtos de boa qualidade de pescado, mas o alto preço e a falta de hábito do consumo são fatores que restringem a frequência de consumo.

\section{Abstract}

This study was conducted to identify the factors related to the consumption of fish at the São Paulo Municipal Market. For this, 100 people were interviewed, 65 women and 35 men. Respondents answered a questionnaire prepared with open- and closed-ended questions on general characteristics of the consumer and with regard to fish consumption habits. Data from the survey were tabulated with spreadsheet editing software, and from the data, graphs and tables were constructed. Most respondents were women and lived in and came from the São Paulo municipality. Half of the respondents reported rarely going to the market, and those that go frequently, indicated that the variety and quality of the products are important factors in the São Paulo Municipal Market. It was observed that the factors that hinder fish consumption are the price and the lack of habit of eating fish. It was concluded that the municipal market is a place with many choices and good quality fish products, but that the high price and the lack of habit of fish consumption are factors that can affect the frequency of consumption. 
Fernanda Maldonado ${ }^{1}$

Celia Alas Rossi

Aparecida Dolores Veornes ${ }^{3}$

Vanessa Aparecida Feijó de Souza ${ }^{4}$

Rosely Bianca dos Santos Kuroda ${ }^{4}$

Vanessa Cristinne Victor Rabaquim ${ }^{5}$

Ana Julia Silva e Alves ${ }^{4}$

\section{Palavras-chave}

Mercado Municipal. Hábitos. Pescado. Preferência. Decisão de compra.

\section{Keywords}

Municipal Market. Habits. Fish consumption.

Choice. Buying decision.

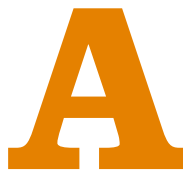

tualmente, a busca por alimentos saudáveis vem crescendo no Brasil e o pescado tem se tornado uma excelente opção por ser considerado uma fonte natural de proteínas e nutrientes (SILVA; GONÇALVES, 2012). Entende-se por pescado peixes, crustáceos, moluscos, anfíbios, quelônios e mamíferos de água doce ou salgada destinados à alimentação humana (BRASIL, 1952).

O potencial brasileiro para a produção de pescado é interessante, visto que o país possui uma costa marítima ampla, cerca de cinco milhões de hectares de terras alagadas na forma de reservatórios e tem aproximadamente $12 \%$ de toda a água doce do mundo, além de abrigar grande quantidade de espécies nativas (BRASIL, 2015). O consumidor desse produto final pode adquiri-lo em supermercados, feiras livres e mercados, congelado ou fresco.

O Mercado Municipal Paulistano (MMP), conhecido como "Mercadão", é um dos edifícios mais emblemáticos da capital paulistana, localizado às margens do Rio Tamanduateí (SÃO PAULO, 2015a,b). O local é um ponto turístico constituído por uma diversidade geográfica, cultural e gastronômica. Conta com 1.600 funcionários, os quais movimentam 350 toneladas de alimentos por dia em seus mais de 290 boxes, recebendo uma média de $15 \mathrm{mil}$ visitantes (SÃO PAULO, 2016). A partir dos fatores listados acima, surge a necessidade de se entender mais os hábitos e preferências dos consumidores para que haja uma consolidação efetiva da cadeia de pescado no país (SÃO PAULO, 2015a,b).

1 Médica-veterinária autônoma

2 Médica-veterinária, Mercado Municipal de São Paulo.

3 Administração, Mercado Municipal de São Paulo.

4 Docente. Doutorado em Epidemiologia Experimental Aplicada às Zoonoses, Centro Universitário das Faculdades Metropolitanas Unidas, São Paulo.

5 Médica-veterinária. Estudante de Mestrado, Faculdade de Medicina Veterinária e Zootecnia, Universidade de São Paulo. 
As pesquisas com consumidores são fontes geradoras de dados de interesse para a indústria de processamento de pescado e os comerciantes. $\mathrm{O}$ campo de pesquisa com consumidores oferece informações sobre expectativas em relação aos produtos. Além disso, a caracterização dos fatores relacionados com o consumo do pescado pode auxiliar na melhora das variáveis analisadas a fim de promover o incremento do consumo desse produto. Para tanto, o presente trabalho foi delineado para caracterizar os fatores relacionados com a decisão de compra, hábitos e preferências para o consumo de pescado entre os frequentadores do MMP.

\section{Material e métodos}

As entrevistas foram realizadas durante os meses de janeiro e fevereiro de 2015, aos sábados. Os entrevistados foram abordados próximos às bancas de peixarias, onde responderam a um questionário previamente construído. Elaborou-se um questionário de múltipla escolha, contendo 18 questões, das quais 17 eram fechadas e uma aberta. Na questão aberta foram obtidas as respostas mais utilizadas para a análise.

As entrevistas foram realizadas por um único pesquisador, o que permitiu a obtenção de um padrão de procedimentos e a redução dos erros inespecíficos e inerentes ao subjetivismo (VASCONCELLOS et al., 2013).

As questões foram subdivididas em duas partes; a primeira sobre as características do consumidor, tais como cidade e bairro de residência, cidade de origem, faixa etária e sexo. A segunda parte abordava a frequência do consumidor ao MMP: razão pela qual vai ao mercado, tipo de carne mais consumida habitualmente, frequência, motivos para o consumo ou não, características observadas na compra, local de aquisição mais comum, preferência de apresentação no momento da compra, preferência no modo de preparo, local de consumo, espécie de consumo e sugestão para se despertar um maior interesse da população por esse produto.

A partir das informações obtidas, registraram-se os dados em planilhas eletrônicas e foi realizada uma análise estatística descritiva, por meio de tabelas e gráficos junto ao programa Microsoft Excel 2007.

A localização do Mercado Municipal de São Paulo foi georreferenciada e plotada em um mapa temático pelo software Quantum Gis (Mapa 1).

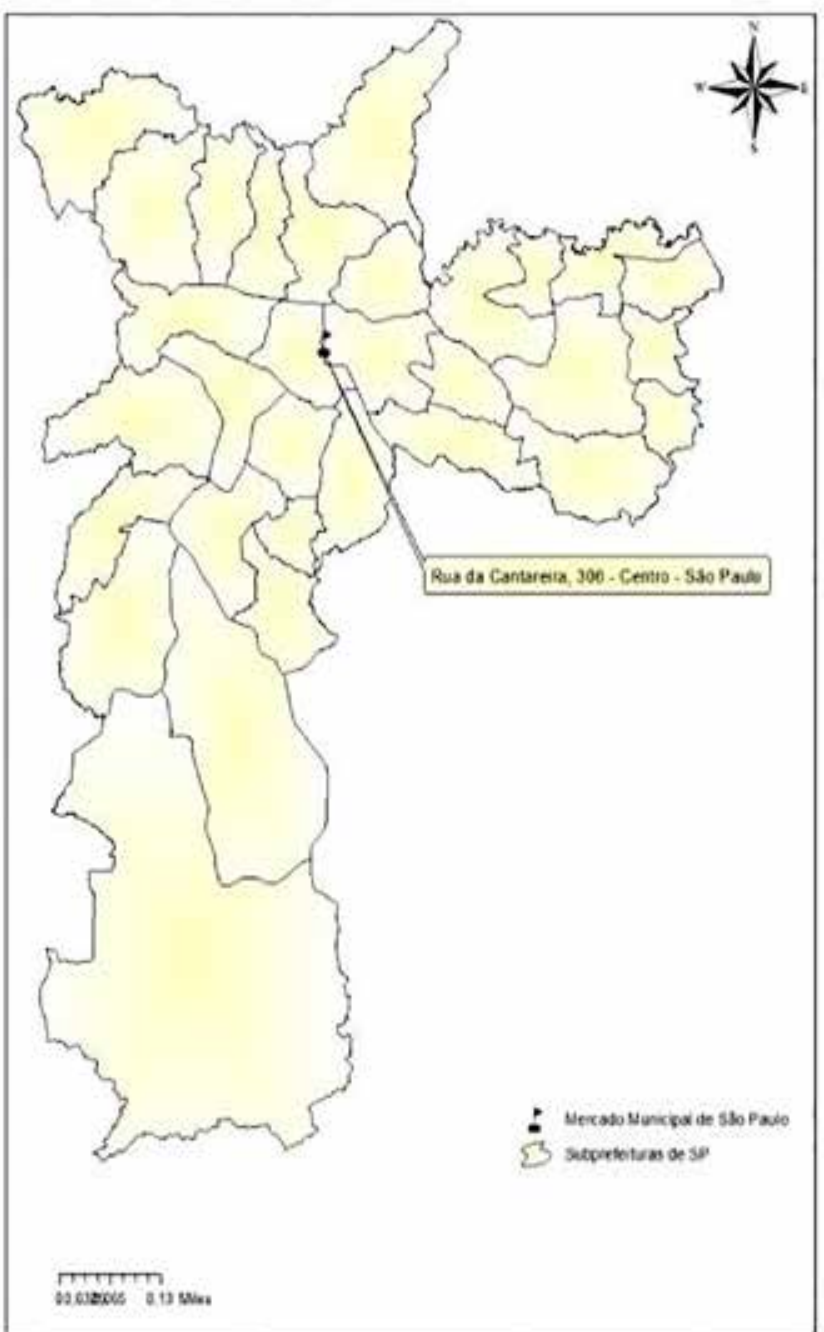

Mapa 1 - Localização do Mercado Municipal da cidade de São Paulo, Brasil. Fonte: Rabaquim (2016). Solicitar a referência ao autor.

\section{Resultados}

\section{Informações sobre o consumidor}

Apesar de o local ser turístico, a maioria $(n=86)$ dos consumidores entrevistados residia no município ou na Grande São Paulo e seis residiam no interior do Estado de São Paulo. Seis entrevistados residiam nas regiões Norte ou Nordeste do Brasil, um na região Sul ou Sudeste e um fora do país. Com relação à região de residência, dos entrevistados que residiam na cidade de São Paulo (76\%), $25 \%$ moravam na zona central; $23,7 \%$ na zona sul; $18,0 \%$ na zona norte; $17,1 \%$ na zona leste e $15,8 \%$ na zona oeste.

Quanto à localização da cidade de origem dos entrevistados, constatou-se que $57 \%$ dos entrevistados são do município e arredores de São Paulo, 16\% são da região Norte e Nordeste do país, 12\% são do interior do Estado de São Paulo, 8\% das regiões Sul ou Sudeste do país, 3\% 
do exterior, $2 \%$ da região Centro-Oeste do país e $2 \%$ são do litoral do Estado de São Paulo.

Em relação à faixa etária, $28 \%$ dos entrevistados tinham idade superior a 50 anos; $27 \%$ de 41 a 50 ano; $22 \%$ de 31 a 40 anos; $19 \%$ de 20 a 30 anos e apenas $4 \%$ eram menores de 19 anos. Relacionando a frequência de consumo por semana com a idade cronológica, foi constatado que a faixa etária acima de 50 anos consome pescado pelo menos três vezes por semana.

Dos 100 entrevistados, 65 eram mulheres e 35 homens. Da população feminina entrevistada, $29,2 \%$ possuía entre 41 a 50 anos; $27,7 \%$ mais do que 50 anos; $24,6 \%$ entre 31 a 40 anos; $15,4 \%$ entre 20 a 30 anos e $3,1 \%$ era menor de 19 anos. Paralelamente, da população masculina entrevistada, $28,6 \%$ tinha idade superior a 50 anos; $25,7 \%$ entre 20 a 30 anos; $22,9 \%$ entre 41 a 50 anos; $17,1 \%$ entre 31 a 40 anos e $5,7 \%$ era menor de 19 anos.

\section{Frequência de visita ao MMP}

Merece atenção a frequência de visitas ao MMP: 50\% dos clientes relatam que raramente vão ao mercado; $24 \%$ vão de uma a três vezes por mês; $20 \%$ de uma a três vezes por ano e apenas $6 \%$ uma vez por semana ou mais (Gráfico 1).
Os principais motivos para frequentar o MMP, segundo os entrevistados, foram: variedade (21\%) e qualidade dos produtos (19\%). Outros motivos citados foram: turismo (13\%), consumo de produtos diferenciados como pastel e sanduíche de mortadela (7\%) e negócios (3\%). Já os principais motivos para não visitar o MMP com maior frequência foram: distância (17\%), difícil acesso ao estacionamento (19\%), falta de tempo (4\%), preço elevado (3\%) e falta de hábito $(2 \%)$.

\section{Informações sobre hábitos de consumo de pescado}

Em relação aos hábitos de consumo de carne, a carne de pescado ficou em $3^{\circ}$ lugar $(23 \%)$, superada pela carne bovina $(48 \%)$ e de aves (24\%). Por último, na 4 a posição, ficou a suína (3\%) (Gráfico 2). Dentre os homens entrevistados, 51,4\% relataram consumir mais vezes a carne bovina, enquanto $22,8 \%$ consumiam com maior frequência a de pescado, $20 \%$ a de aves, $2,9 \%$ a suína e $2,9 \%$ não consumiam proteína de origem animal.

A maioria dos entrevistados (52\%) consumia a carne de pescado de uma a três vezes por semana; $20 \%$ consumiam de uma a três vezes por mês; $11 \%$ de quatro a seis vezes por semana; $9 \%$ não consumiam; $6 \%$ consumiam raramente (com uma frequência menor que uma vez por mês) e $2 \%$ dos entrevistados não consumiam nenhum tipo de carne.

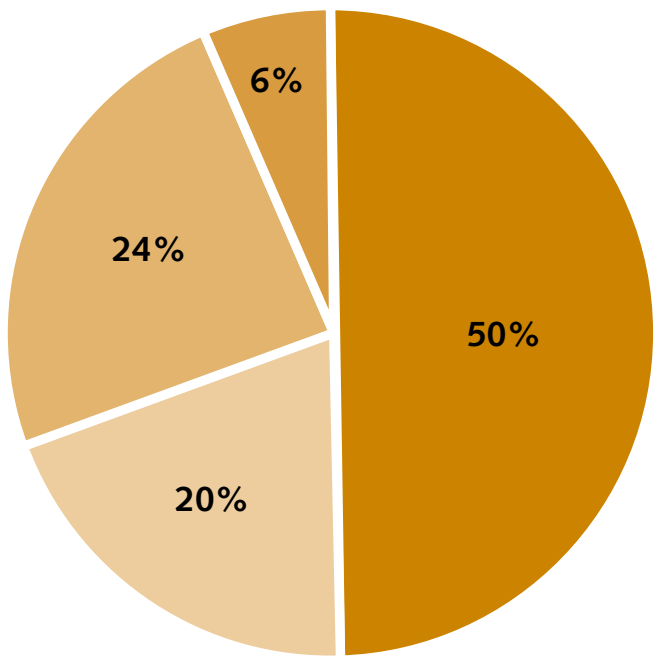

Raramente

1 a 3 vezes por mês

1 a 3 vezes por ano

1 vez por semana ou mais

Gráfico 1 - Frequência de visitas ao MMP pelos entrevistados.

Fonte: Maldonado (2016). Solicitar a referência ao autor. 
Quanto às razões que levavam os entrevistados ao consumo de pescado, foi constatado que 35\% dos frequentadores consumiam pescado pelo benefício à saúde; $32 \%$ pelo prazer em comer; $18 \%$ para variar o cardápio; $3 \%$ pela fácil digestão; $2 \%$ por ser uma carne branca; $1 \%$ pela falta de opção e $9 \%$ dos entrevistados não consumiam carne de pescado (Gráfico 2).

Os motivos para não se consumir pescado foram: preço alto (35\%); falta de hábito (19\%); difícil preparo (15\%); falta de sabor (9\%); $17 \%$ por motivos variados (não gosta do cheiro, não gosta de variar o cardápio, não acha necessário) e $5 \%$ não informaram o motivo.

Ao avaliar quais considerações e características eram levadas em consideração no momento da compra do pescado, a maioria dos entrevistados (38\%) considerou, principalmente, a qualidade do produto; $24 \%$ considerou mais relevante o sabor; $17 \%$ o preço; $9 \%$ os benefícios à saúde; $5 \%$ o modo de preparo do pescado e $7 \%$ não informou.

O local de preferência para adquirir pescado habitualmente foi o supermercado (47\%), peixaria (18\%), mercado municipal (15\%), feiras livres (13\%) e $7 \%$ dos entrevistados não informaram.

Em relação ao local de consumo, 50\% dos entrevistados preferiam consumir pescado em restaurantes ou nas residências; $31 \%$ apenas nas residências; $6 \%$ apenas em restaurantes; $2 \%$ apenas em viagens e $11 \%$ não souberam informar ou tanto fazia.
Quanto à importância da forma de apresentação do produto para a decisão de compra entre os que consumiam pescado, $47 \%$ preferiam o pescado cortado em filé, $23 \%$ o pescado inteiro, $20 \%$ cortes específicos, $3 \%$ enlatados e $7 \%$ dos entrevistados não informaram.

Acerca do modo de preparo, a maioria dos entrevistados $(\mathrm{n}=52)$ tinha preferência por preparar o pescado assado; 24 preferiam o pescado frito; $11 \mathrm{o} \mathrm{cru;} \mathrm{sete} \mathrm{não}$ informaram e apenas seis preferiam preparar o pescado na forma cozida.

Na relação do gênero dos consumidores com a forma de preparo, foi constatado que tanto homens quanto mulheres preferiam o pescado assado; logo em seguida, frito para as mulheres e cru para os homens (vv).

Quanto aos tipos de peixes consumidos com maior frequência, os dez tipos de pescado mais citados foram: Salmão (15\%), Tilápia (11\%), Pescada branca (11\%), Merluza (8\%), Atum (7\%), Cação (7\%), Badejo (4\%), Dourado (4\%), Bacalhau (3\%) e Linguado (3\%).

A única questão aberta aplicada solicitava aos entrevistados uma sugestão para o aumento do consumo de pescado no Brasil. A maioria dos entrevistados sugeriu a redução no preço do produto (49\%), seguido do aumento do incentivo de consumo desse produto às crianças e a melhora na qualidade do produto, ambas com $10 \%$. Outras sugestões foram melhorar a divulgação do produto com relação aos benefícios à saúde (8\%),

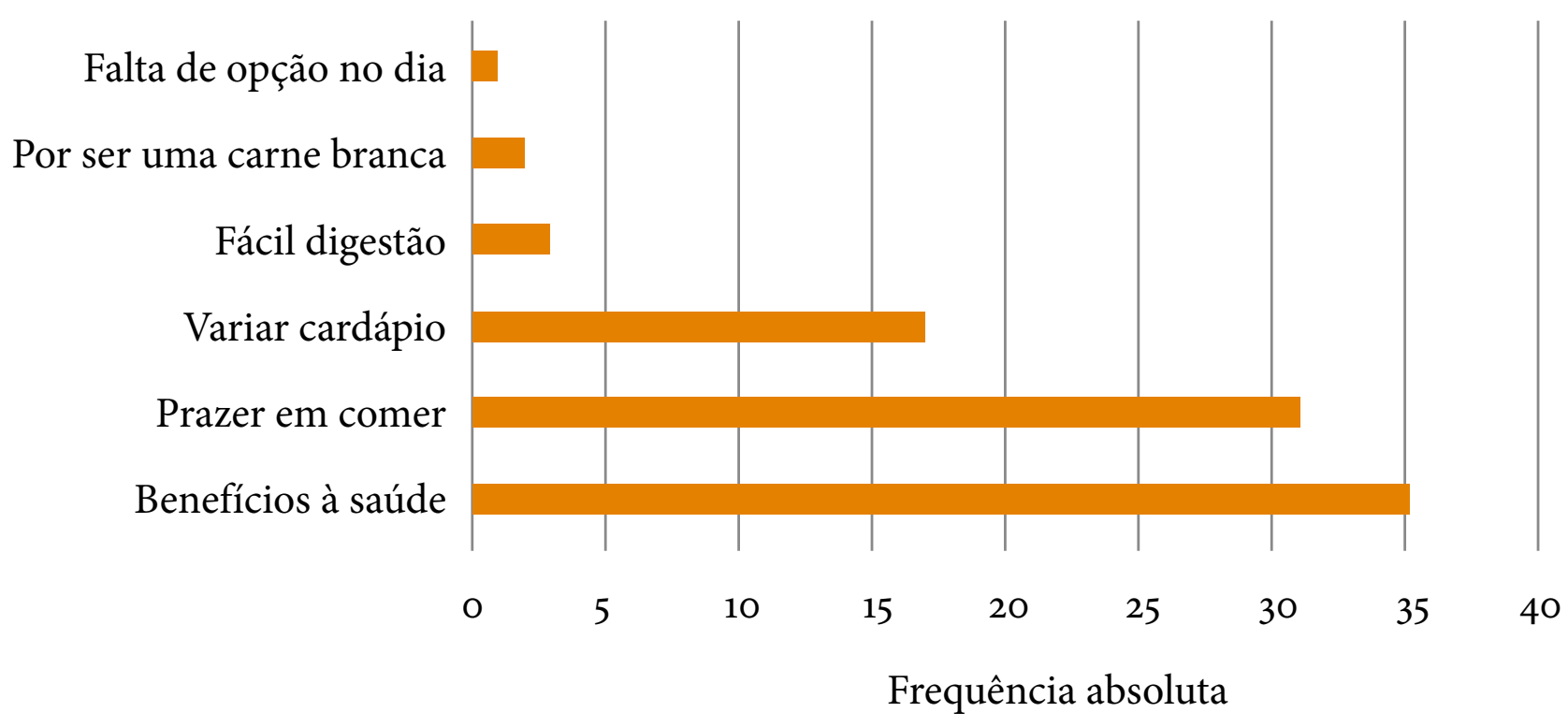

Gráfico 2 - Razões para o consumo de pescado pelos consumidores de MMP. Fonte: Maldonado (2016). Solicitar a referência ao autor. 


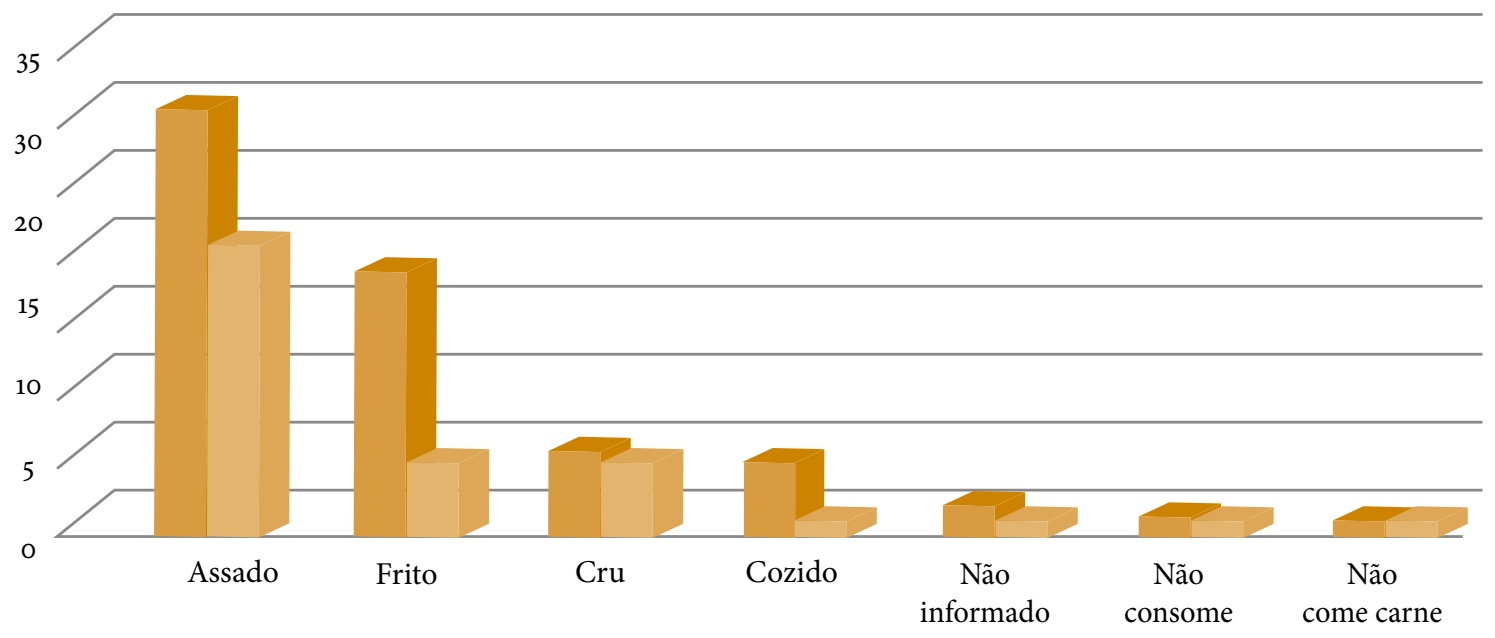

Gráfico 3 - Preferência no modo de preparo do pescado pelos entrevistados.

Fonte: Maldonado (2016). Solicitar a referência ao autor.

incrementar a exposição do produto no comércio, tornando-a mais atrativa (7\%), e incentivar a produção por meio de aquicultura (3\%).

\section{Discussão}

A análise das relações existentes entre a idade cronológica dos consumidores de pescado e a frequência de consumo desse tipo de alimento revelou que, os consumidores de idade mais elevada apresentaram uma atitude mais positiva com relação ao consumo de pescado. Resultado semelhante foi obtido na Noruega por Olsen (2003).

Salienta-se que, na Bélgica, Trondsen et al. (2004) e Verbeke e Vackier (2005) identificaram que os hábitos alimentares estão diretamente relacionados à faixa etária e ao sexo, principalmente, mulheres com faixa etária mais avançada (45 a 60 anos), resultado semelhante ao encontrado entre os consumidores do |Mercado Municipal de

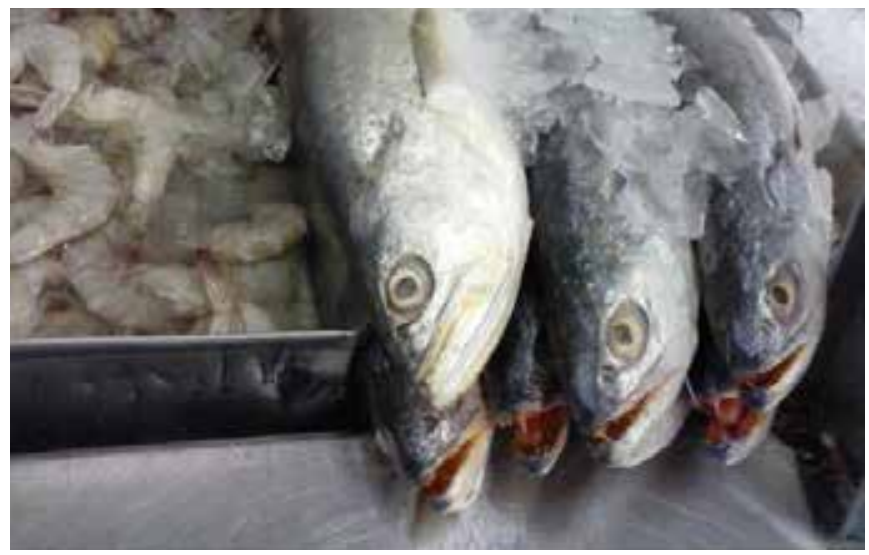

São Paulo. Porém, esse resultado difere do obtido por Rocha-Neto (2010), em Macapá, no Amapá, em relato de que a maioria dos frequentadores das peixarias da cidade era homem, por alegarem reconhecer melhor a qualidade do pescado e pela baixa frequência de mulheres em locais com odor pouco agradável. Apesar da baixa frequência de mulheres nas peixarias, não necessariamente elas consomem menos o produto.

Com relação à avaliação do consumo de diferentes espécies, este trabalho relata que a ordem das fontes de proteína animal mais consumidas pelos entrevistados é: carne bovina, aves, pescado e, por fim, suína. O resultado difere do verificado por Tavares et al. (2013) que, em estudo realizado na cidade de Belo Horizonte (MG), relatou ser a carne de pescado a menos consumida.

Vasconcellos et al. (2013) relatam que o tipo de peixe mais consumido nas feiras livres de Santo André (SP) foram Sardinha e Cação, diferentemente do verificado neste estudo, no qual a Sardinha nem foi citada e o Cação ficou somente na $6^{\mathrm{a}}$ posição entre os mais consumidos.

Surpreendentemente, a maioria dos consumidores ingeria pescado de uma a três vezes por semana, semelhante à análise de Rocha-Neto (2010), em Macapá, ao afirmar que $62 \%$ dos entrevistados consumiam pescado de uma a duas vezes por semana. Tavares et al. (2013), em Belo Horizonte (MG), levantaram que a maior parte dos entrevistados preferia consumir o pescado frito, seguido de assado e, por fim, cozido - diferentemente do constatado no presente trabalho, no qual o pescado assado foi o preferido entre os consumidores do MMP. 


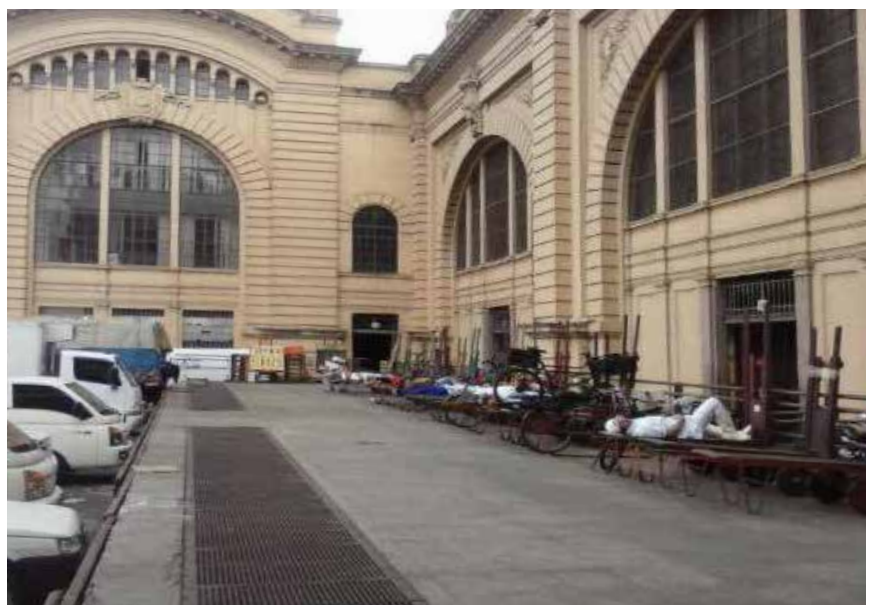

No Estado do Pará, Costa, Almeida e Oliveira (2006) relataram que a decisão de compra de pescado pelos consumidores estava fortemente relacionada ao preço do produto, visto que o principal motivo alegado pelo consumidor para não consumir pescado foi o preço elevado, o que também foi observado no presente trabalho. Da mesma forma, Vasconcellos et al. (2013), em estudo nas feiras livres na cidade de Santo André (SP), relatam que o preço elevado é um fator determinante para o consumo do pescado.

\section{Conclusão}

A maioria dos fregueses do Mercado Municipal de São Paulo que tinha por hábito adquirir e consumir pescado era do gênero feminino e com idade superior a 50 anos, apresentando uma frequência de consumo de pescado de uma a três vezes por semana. O Salmão foi a espécie de peixe preferida pelos consumidores entrevistados. Dentre razões para a baixa frequência do consumo, os entrevistados pontuaram a falta de hábito e o preço elevado, se comparado às outras carnes, como a bovina e a de aves.

Conclui-se, portanto, que o Mercado Municipal de São Paulo é um local com variedade e boa qualidade de pescados, mas o alto preço e a falta de hábito de consumo são fatores que restringem o aumento da frequência de consumo do produto.

\section{Referências}

BRASIL. Decreto n. 30.691, de 29 de março de 1952. Regulamento de inspeção industrial e sanitária de produtos de origem animal. Brasil, 1952. Disponível em: <http://www. agricultura.gov.br/arq_editor/file/Desenvolvimento_Sustentavel/Producao-IntegradaPecuaria/Decreto\%2030691\%20de\%201952.pdf>. Acesso em: 18 mar. 2015.

Ministério da Pesca e Aquicultura. Pesca. Brasil, 2015. Disponível em: <http:// www.mpa.gov.br/index.php/pesca>. Acesso em: 18 mar. 2015

COSTA, A. D.; ALMEIDA, I. C.; OLIVEIRA, J. S. Mercado e perfil do consumidor de peixe no estado do Pará. In: CONGRESSO DA SOCIEDADE BRASILEIRA DE ECONOMIA, ADMINISTRAÇÃO E SOCIOLOGIA RURAL, 44., 2006, Fortaleza. Anais... Fortaleza: Sober, 2006. Disponível em: <http://www.sober.org.br/palestra/13/588.pdf>. Acesso em: 18 mar. 2015

OLSEN, S. O. Understanding the relationship between age and seafood consumption: The mediating tole of attitude, health involvementand convenience. Food Quality and Preference, Harlow, Essex, Uk, v. 14, n. 3, p. 199-209, Apr. 2003.

ROCHA-NETO, A. P. Fatores que influenciam na decisão de compra de pescado nas feiras livres de Macapá - AP. 2010. 38 f. Monografia (TCC em Extensão Pesqueira). Coordenação do Curso de Engenharia de Pesca, Universidade do Estado do Amapá, Macapá, 2010.

SÃO PAULO (CIDADE). Prefeitura de São Paulo. História do Mercado Municipal Paulistano. São Paulo, 2015a. Disponível em: <http://www.prefeitura.sp.gov.br/ portal/a_cidade/historia/index.php?p=5978>. Acesso em: 10 mar. 2015.

SÃO PAULO. Prefeitura de São Paulo. Portal do Mercadão. São Paulo, 2016. Disponível em: <http://www.oportaldomercadao.com.br/index.php?page=institucional>. Acesso em: 15 maio 2016

Prefeitura de São Paulo - Turismo. Mercado Municipal Paulistano. São Paulo, 2015b. Disponível em: <http://www.cidadedesaopaulo.com/sp/br/o-que-visitar/ atrativos/pontos-turisticos/4346-mercado-municipal>. Acesso em: 17 mar. 2015

SILVA, D. C. F.; GONÇALVES, A. A. Perfil de consumo de pescado dos usuários do restaurante universitário da UFERSA. Revista Caatinga, Mossoró, v. 25, n. 3, p. 125-129, jul./set. 2012.

TAVARES, G. C. et al. Perfil do consumo de pescado na cidade de Belo Horizonte, MG. Boletim de Indústria Animal, Nova Odessa, v. 70, n. 3, p. 230-236, 2013

TRONDSEN, T. et al. Health and seafood consumption patterns among women aged 45-69 years. A Norwegian seafood consumption study. Food Quality and Preference, Harlow, Essex, Uk, v. 15, p. 117-128, Feb. 2004.

VASCONCELLOS, J. P. et al. Individual determinants of fish choosing in open-air street markets from Santo André, SP/Brazil. Appetite, London, v. 68, p. 105-111, Sept. 2013.

VERBEKE, W.; VACKIER, I. Individual determinants of fish consumption: application of the theory of planned behavior. Appetite, London, v. 44, n. 1, p. 67-82, Feb. 2005. 
RESUMOS

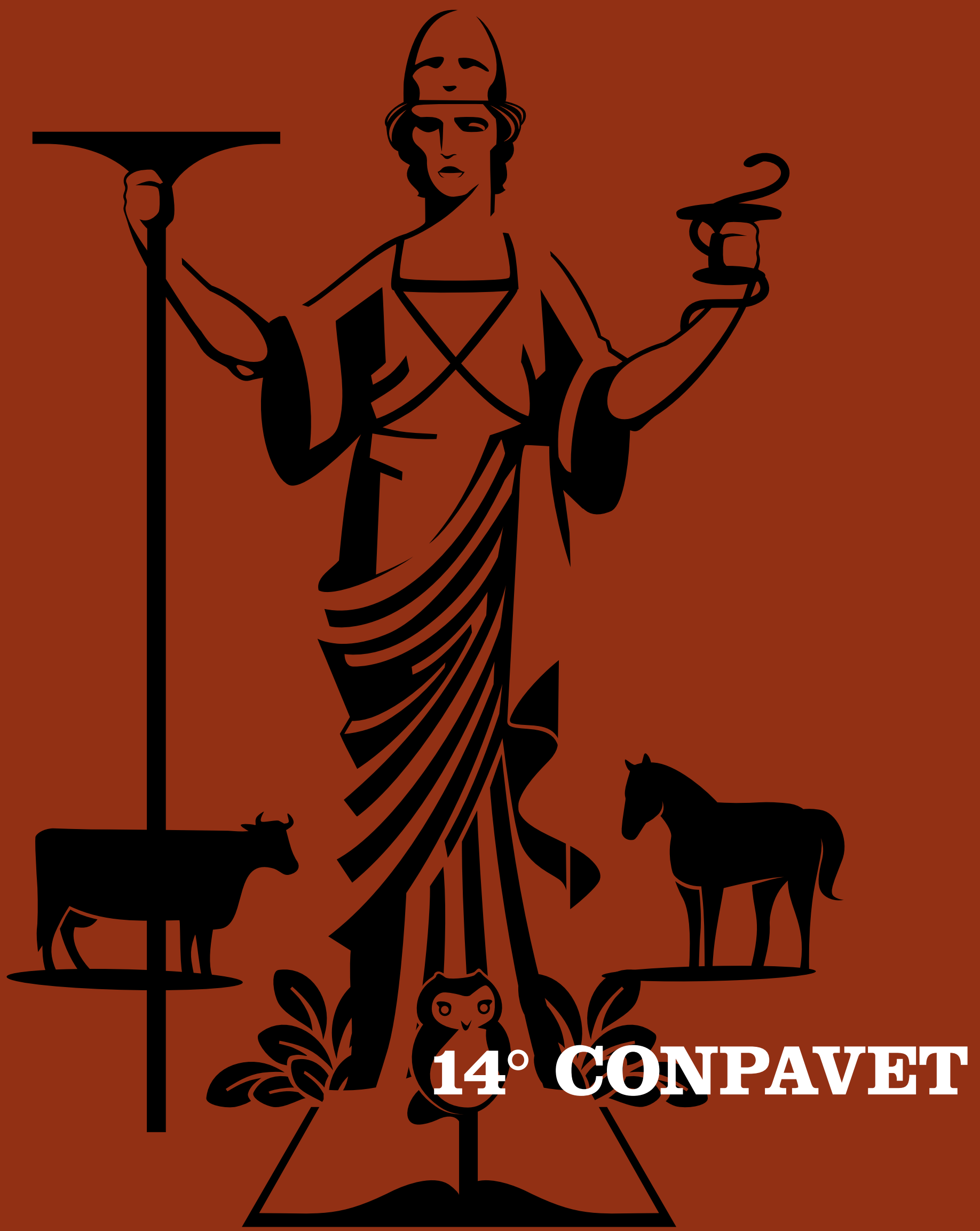

